Obere Extremität $2021 \cdot 16: 2-7$ https://doi.org/10.1007/s11678-021-00626-z Received: 10 November 2020

Accepted: 15 January 2021

Published online: 16 February 2021

(c) The Author(s) 2021

Benedikt Schliemann ${ }^{1}$ (D) $\cdot$ Marvin Minkus $^{2} \cdot$ Dominik Seybold $^{3} \cdot$ Markus Scheibel $^{2}$

' Department of Trauma, Hand and Reconstructive Surgery, University Hospital Münster, AlbertSchweitzer-Campus 1, building W1, Münster, Germany

${ }^{2}$ Center for Musculoskeletal Surgery, Charité - Universitätsmedizin Berlin, Berlin, Germany

${ }^{3}$ OPND Düsseldorf, Düsseldorf, Germany

\title{
Conservative management of first-time traumatic anterior shoulder dislocation
}

than $50 \%$, conservative treatment strategies will prevent unnecessary surgery in the other half of the patients [10].

\section{Internal vs. external rotation}

\section{Immobilization in internal rotation}

Rowe reported in 1963 on recurrence rates of up to $95 \%$ in patients under the age of 20 years, these rates have not changed over time, at least if the dislocation is managed conservatively [1-8]. Young (15-30) and active male patients are still the group with both the highest incidence $(\approx 50 \%$ of all dislocations) and highest risk of recurrence $(\approx 65 \%)$ after conservative treatment of traumatic anterior shoulder dislocation [9].

To date, there is no clear consensus on which patients should be treated conservatively. However, there is clear evidence in the literature that surgical treatment is superior to conservative treatment for anterior shoulder instability: the most recent systematic review and meta-analysis revealed that, overall, the recurrence rate is significantly lower after surgical treatment $(9.7 \%$ vs. $67.4 \%)$ [8]. Moreover, the risk of secondary interventions is significantly higher after initial conservative management ( $5.9 \%$ vs. $46.7 \%$ ). This indicates that successful surgical intervention is the most effective treatment. However, the risk of recurrence decreases with higher age and lower activity levels, indicating that there is a group of patients that may be suitable for successful conservative management. Given that the overall recurrence rate is no higher
Since its early description by Hippocrates, the reduced shoulder was immobilized in internal rotation, fixed to the trunk, later referred to as the Gilchrist position (named after the US dermatologist Thomas C. Gilchrist). It was assumed that with the arm in adduction and internal rotation, the shoulder remains safely reduced, since it is the opposite of the abduction-external rotation position in which dislocation usually occurs. If the treatment remains conservative, immobilization in internal rotation is usually carried out for 1-3 weeks $[9,11,12]$. Longer immobilization was not able to reduce the risk of recurrence $[13,14]$. However, the high recurrence rates reported in the literature relate to this method of immobilization. This is attributed to failure of the anteroinferior labroligamentous complex to heal in its anatomic insertion site at the glenoid rim. The labrum will remain in a medialized position and finally heal to the scapular neck. Therefore, the labrum loses its function as a static restraint against anterior dislocation. This indicates that the rehabilitation protocol is of great importance, since active stabilizers such as the rotator cuff and other surrounding muscles of the shoulder girdle need to compensate for the missing stabilization by the labrum. Unfortunately, in most of the studies dealing with instability, post-immobilization rehabilitation is only poorly described [11]. More detailed rehabilitation protocols are only available for patients that underwent surgical treatment [9]. In general, rehabilitation should comprise guided physiotherapy followed by self-exercise until range of motion and strength are comparable to the healthy shoulder [15]. The risk of recurrence is not affected by physiotherapy [16].

\section{Immobilization in external rotation}

Since the first description by Itoi et al., many efforts have been made to assess the effect of external rotation immobilization and to prove its superiority over conventional immobilization in internal rotation [17]. Theoretically, external rotation leads to a reduction of the labrum to the glenoid rim by tensioning of the anterior capsule and subscapularis tendon and a subsequent shift of the joint effusion to the posterior compartment (- Fig. 1).

In their primary clinical study, Itoi et al. found a recurrence rate of $26 \%$ after external rotation immobilization vs. $42 \%$ in the internal rotation group [17]. Since then, many authors have performed similar studies with differing results $[5,6$, $14,18-21]$. In general, external rotation alone did not significantly reduce recurrence rates. It is worth noting that most external rotation braces are not able to maintain their specific rotation. Sullivan 
Hier steht eine Anzeige.

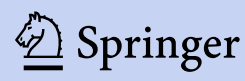



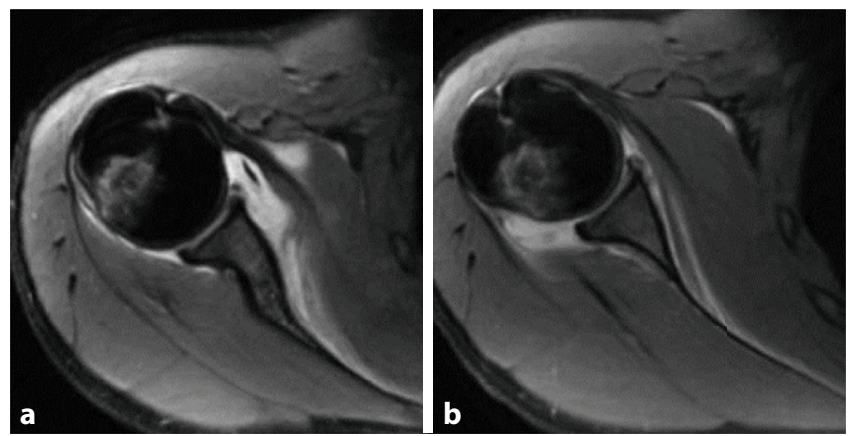

Fig. $1<\mathrm{MRI}$ after anterior dislocation shows a Bankart lesion (a). Reduction of the Bankart lesion with external rotation (b). In addition, the joint effusion shifted to the posterior compartment, allowing the torn labrum to heal
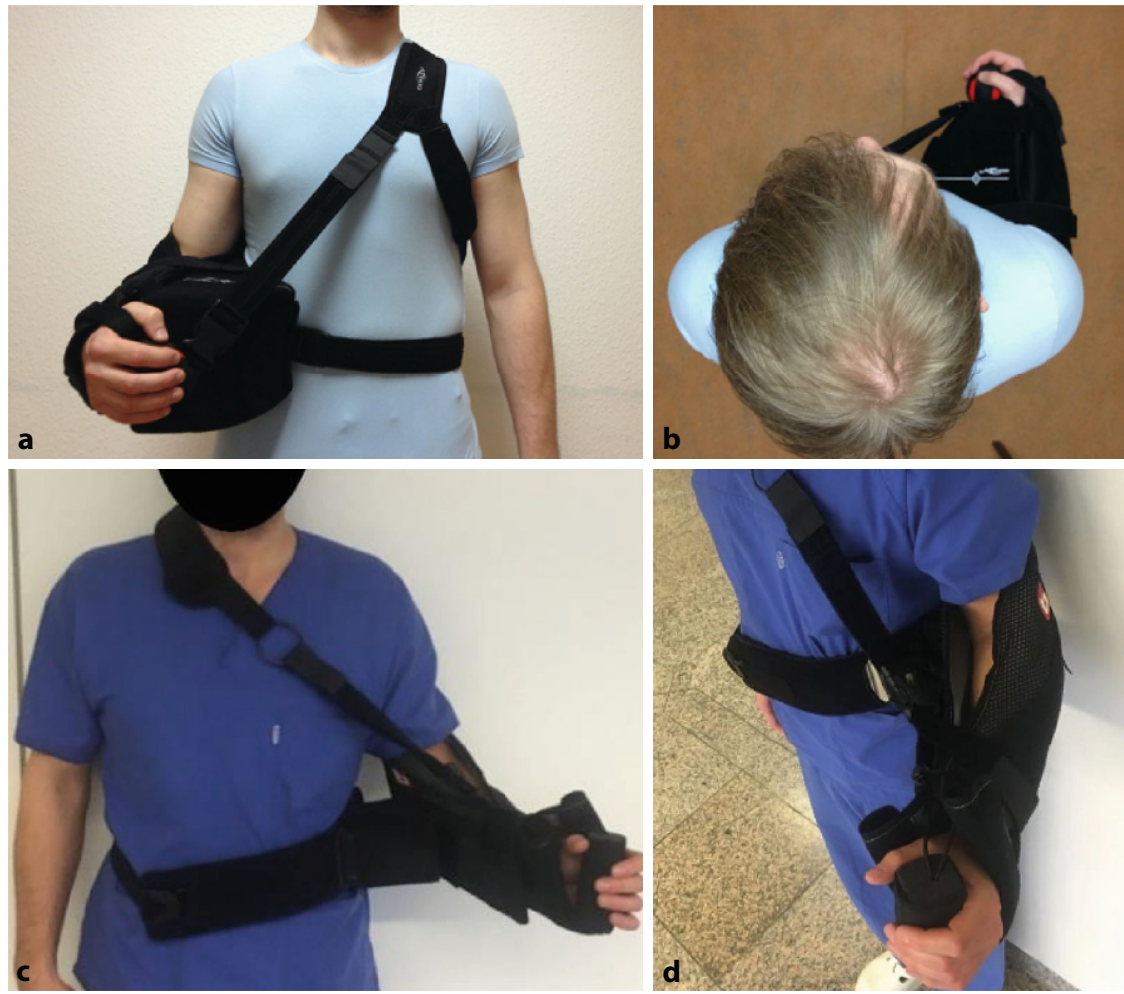

Fig. 2 \ Conventional external rotation brace (Ultrasling ER, DJO, Lewisville, TX, USA; a, b) in comparison to an abduction/external rotation brace (Bledsoe Arc-XR, Bledsoe brace, Pinewood, TX, USA; c, d). (Modified from [18])

et al. assessed different external rotation braces and their ability to achieve and maintain shoulder external rotation [22]. One of the most frequently used braces (Ultrasling ER $15^{\circ}$ ) only maintained $9.4^{\circ}$ of external rotation (- Fig. 2). However, even after immobilization in only slight external rotation, some patients did not sustain a re-dislocation. This indicates that not every type of anterior capsulolabral lesion is suitable for external rotation immobilization [23]. The initial enthusiasm for external rotation immobilization dwindled with the first randomized trials that failed to demonstrate any advantage over internal rotation immobilization $[5,6]$.

However, a combination of external rotation and abduction has proved to be more effective in labral reduction, at least from a biomechanical point of view: In a cadaveric model, Miller et al. investigated the relation between arm position and the contact force between the labrum and the glenoid and found a maximum contact force in $45^{\circ}$ abduction [24]. In contrast, no contact force at all was seen in internal rotation. In addition, Hart and Kelly found the most sufficient reduction of the labrum with a combination of $60^{\circ}$ external rotation and $30^{\circ}$ abduction [25]. This considerable difference is supported by the experimental study by Itoi et al., who assessed the influence of arm position on reduction of the anterior and inferior labrum [26]. Whereas external rotation effectively reduced the anterior labrum, copation of the inferior labrum could only be achieved with abduction. Consequently, the only published randomized controlled trial (RCT), by Heidari et al., comparing immobilization in external rotation and abduction to internal rotation in 102 patients found a significantly different recurrence rate, favoring external rotation/abduction (3.9\% vs. $33.3 \%)$ [27]. In a prospective-randomized multicenter trial by the German Society of Shoulder and Elbow Surgery (DVSE), immobilization in abduction/external rotation was compared to primary arthroscopic labrum repair in 102 patients with an average age of 26 years. After a follow-up of 2 years, the recurrence rate was $19.1 \%$ after immobilization vs. $2.3 \%$ after labrum repair (accepted for publication). No differences could be found for functional scores. In conclusion, the current literature supports immobilization in abduction/external rotation as the most effective approach when conservative management is indicated in younger patients.

With regard to the uncomfortable arm position, compliance with external rotation immobilization is always a major concern. Hatta et al. compared four different braces with regard to comfort and patient acceptance (1, adduction and internal rotation; 2 , adduction and external rotation; $3,30^{\circ}$ abduction and $30^{\circ}$ external rotation; and $4,30^{\circ}$ abduction and $60^{\circ}$ external rotation) [28]. After completing immobilization for $24 \mathrm{~h}$, subjects were asked to evaluate the discomfort of bracing for overall and individual activities. As expected, $60^{\circ}$ abduction and external rotation immobilization was rated the most uncomfortable. Thus, the authors of nearly every systematic review claim that external rotation braces provide less comfort and, therefore, patient compliance will be poor $[7,10,13,29$, 30]. However, in most of the RCTs included in these reviews, the compliance rate of patients treated with external rota- 
tion braces is higher than, or at least equal to, that in the internal rotation group (- Table 1). Therefore, it is of the utmost importance to explain to the patient the benefits of this uncomfortable arm position with regard to the decreased risk of recurrence and, consequently, the decreased risk for surgical interventions. Usually, 3 weeks of immobilization are recommended. Longer immobilization periods are not associated with better results [14].

\section{External vs. internal rotation}

Since the first study by Itoi et al., more RCTs have been published in the literature $[5-7,17,19,21,27]$. While followup is consistently around 24 months, the number of patients included varies considerably from 30 to 180 , and power analyses are lacking in some studies. As mentioned above, the compliance rate was always high in both internal and external rotation groups. Although similar braces were used, the recurrence rate differs between the studies. Approximately half of the studies report better results and lower recurrence rates for the external rotation group, whereas the other half did not find any advantage for external over internal rotation immobilization. - Table 1 provides an overview of the RCTs published on external vs. internal rotation.

Similarly, the most recent reviews on the topic come to different conclusions: while the Cochrane review by Braun and McRobert could not provide evidence that external rotation is superior, the most recent meta-analysis found that external rotation immobilization significantly reduces the recurrence rate in patients older than 20 years of age $[11,30]$. Interestingly, only the latter review incorporated the most recent RCT by Murray et al., who found a lower recurrence rate for the external rotation group $(29.2 \%$ vs. $47.8 \%)$ [19]. This indicates that every other RCT will considerably influence the results of subsequent systematic reviews.

Again, it must be mentioned that the only study that compared internal rotation immobilization with combined immobilization in abduction/external rotation showed the most obvious difference in the recurrence rate, favoring abduc-

Obere Extremität 2021 · 16:2-7 https://doi.org/10.1007/s11678-021-00626-z

(c) The Author(s) 2021

\section{B. Schliemann $\cdot$ M. Minkus $\cdot$ D. Seybold $\cdot$ M. Scheibel}

\section{Conservative management of first-time traumatic anterior shoulder dislocation}

\section{Abstract}

Traumatic anterior shoulder dislocation is a common injury in young and active patients and the proper treatment is still a matter of debate. The recurrence rate after conservative management remains high and, therefore, primary surgical intervention is sometimes recommended in very young patients whose risk of recurrences is highest. Immobilization in external rotation, first described by Itoi, is a promising conservative option as it provides adequate labral reduction and low recurrence rates. Recent meta-analyzes could not unequivocally demonstrate its superiority over internal rotation immobilization. However, biomechanical and early clinical results show a better effect on reduction of the labrum and lower recurrence rates for immobilization in a combination of abduction/external rotation than for external rotation alone. The present article aims to provide an overview of the conservative management of firsttime traumatic shoulder dislocation in order to provide the treating physician or surgeon with the best current evidence as a basis for developing the appropriate treatment strategy for the patient.

\section{Keywords}

Anterior shoulder dislocation - External rotation - Recurrent instability - Internal rotation . Conservative treatment

\section{Konservative Behandlung der traumatischen vorderen Schultererstluxation}

\section{Zusammenfassung}

Die traumatische vordere Schulterluxation ist eine häufige Verletzung bei jungen und aktiven Patienten. Die optimale Behandlung bleibt strittig. Die Rezidivrate nach konservativer Behandlung ist weiterhin hoch. Daher wird bei sehr jungen Patienten, die das höchste Rezidivrisiko haben, manchmal eine primäre operative Intervention empfohlen. Die von Itoi erstbeschriebene Immobilisation in Außenrotation ist eine vielversprechende konservative Option, da sie eine ausreichende Labrumreposition bewirkt und mit geringen Rezidivraten assoziiert ist. Jedoch konnten aktuelle Metaanalysen die Überlegenheit des Verfahrens gegenüber der Immobilisation in Innenrotation nicht eindeutig belegen. Biomechanische und frühe klinische Ergebnisse zeigen aber einen besseren Effekt bezüglich der Labrumreposition und geringere Rezidivraten bei Immobilisation mit kombinierter Abduktion und Außenrotation verglichen mit der alleinigen Außenrotation. Der vorliegende Beitrag soll die konservative Versorgung bei traumatischer Schultererstluxation zusammenfassen und dem behandelnden Arzt oder Chirurgen die beste aktuelle Evidenz bieten, damit er auf dieser Grundlage die geeignete Behandlungsstrategie für den jeweiligen Patienten entwickeln kann.

\section{Schlüsselwörter}

Vordere Schulterluxation - Außenrotation . Rezidivierende Instabilität · Innenrotation . Konservative Therapie tion/external rotation therapy (33.3 vs. $3.9 \%)$ [27].

\section{Return to play after conservative treatment}

Again, there is no consensus on when an athlete is able to return to play after conservative management of anterior shoulder dislocation [10]. After immobilization until the athlete is free of pain, physiotherapy should be started. As a main criterion, range of motion and strength should be nearly normal and symmetric to the healthy shoulder $[9,10]$. In particular, weakness in internal and external rotation seems to have a negative predictive value [31]. Return to play may be possible within as little as 2-3 weeks. In a study focusing on return to play of National Basketball Association athletes, all athletes could return to play. The average time from injury to return to play was 7.8 weeks after conservative 


\begin{tabular}{|c|c|c|c|c|c|c|c|c|}
\hline Study & Year & $\begin{array}{l}\text { n ER/IR } \\
\text { (complete } \\
\text { follow-up) }\end{array}$ & Age ER/IR & $\begin{array}{l}\text { MRI } \\
\text { (no/yes) }\end{array}$ & $\begin{array}{l}\text { Follow-up } \\
\text { (months) }\end{array}$ & $\begin{array}{l}\text { Recurrence } \\
\text { rate ER/IR (\%) }\end{array}$ & $\begin{array}{l}\text { Compliance } \\
\text { rate ER/IR (\%) }\end{array}$ & Specifics \\
\hline Itoi et al. & 2007 & $85 / 75$ & $35 / 37$ & No & Min. 24 & $\begin{array}{l}26 / 42 \\
(p=0.033)\end{array}$ & $88 / 70$ & $\begin{array}{l}\text { Relative risk reduction overall } \\
36.2 \& \text {, age group }<30 \text { y: } 46.1 \%\end{array}$ \\
\hline $\begin{array}{l}\text { Taskoparan } \\
\text { et al. }\end{array}$ & 2010 & $16 / 17$ & $\begin{array}{l}63.6 \% \text { Between } \\
21-30 \text { years }\end{array}$ & Yes & 24 & $\begin{array}{l}6.3 / 29.4 \\
(p=0.05)\end{array}$ & $\mathrm{n} / \mathrm{a}$ & $\begin{array}{l}\text { Subgroup } 21-30: 0 \text { (ER) vs. } 5 \text { (IR) } \\
\text { re-dislocations }(p=0.035)\end{array}$ \\
\hline $\begin{array}{l}\text { Heidari } \\
\text { et a.I }\end{array}$ & 2014 & $51 / 51$ & $35 / 36$ & No & 24 & $\begin{array}{l}3.9 / 33.3 \\
(p<0.01)\end{array}$ & $80 / 94$ & $\begin{array}{l}\text { AbER! } \\
\text { Subgroup aged } 31-40 \text { years: } \\
44.8 \% \text { in the AdIR group vs. } 3.8 \% \\
\text { in the AbER group, }(p<0.001)\end{array}$ \\
\hline $\begin{array}{l}\text { Murray } \\
\text { et al. }\end{array}$ & 2020 & $24 / 23$ & $26.6 / 27.4$ & No $(C T)$ & 24 & $\begin{array}{l}29.2 / 47.8 \\
(p=0.188)\end{array}$ & $92 / 87$ & $\begin{array}{l}20-40 \text { Years subgroup: IR } 50 \% \text { vs. } \\
\text { ER } 6.4 \% ;(p=0.044)\end{array}$ \\
\hline $\begin{array}{l}\text { Finestone } \\
\text { et al. }\end{array}$ & 2009 & $27 / 24$ & 20.3 Overall & $\mathrm{n} / \mathrm{a}$ & $\begin{array}{l}33(35.8 \mathrm{ER} \\
\text { vs. } 30.8 \mathrm{IR})\end{array}$ & $\begin{array}{l}37 / 41.7 \\
(p=0.74)\end{array}$ & $100 / 100$ & - \\
\hline Livaag et al. & 2011 & $91 / 93$ & 26.8 Overall & $\mathrm{n} / \mathrm{a}$ & $\begin{array}{l}29.1(29.5 \mathrm{ER}, \\
28.9 \mathrm{IR})\end{array}$ & $\begin{array}{l}30.8 / 24.7 \\
(p=0.036)\end{array}$ & $67.7 / 47.4$ & - \\
\hline Whelan & 2014 & $27 / 25$ & $23 / 23$ & No & $25(12-43)$ & $\begin{array}{l}22 / 32 \\
(p=0.42)\end{array}$ & $80 / 80$ & - \\
\hline
\end{tabular}

ER external rotation, IR internal rotation, $M R I$ magnetic resonance imaging, $C T$ computed tomography, AbER abduction/external rotation, AdIR adduction/ internal rotation

management vs. 19 weeks after surgery. However, athletes who underwent conservative treatment were more likely to re-dislocate earlier [32]. This is similar for National Football League athletes: the mean interval between the dislocation and return to play after conservative management was only 3 weeks ( 39 weeks after surgical management). The recurrence rate was significantly higher (55\% vs. $26 \%$ ) and the interval between the index dislocation and the first recurrence was only 2.8 weeks [33]. Additionally, there is evidence that the outcome is worse if the athlete returns to sports before 6 weeks [34].

\section{Practical conclusion}

- The recurrence rate after conservative management of first-time traumatic anterior shoulder dislocation remains high and strongly correlates to the patient's age at the time of dislocation.

- Biomechanical and imaging studies indicate that immobilization in external rotation, particularly in combination with abduction, improves coaption of both the anterior and inferior labrum to the glenoid rim.

- Some types of lesion (i.e., Perthes) seem to be more suitable for external rotation immobilization than others.
- There is no clear evidence that surgical treatment after the first recurrence leads to poorer results than after first-time dislocation.

- Therefore, conservative treatment can generally be considered.

- However, young patients, particularly $<20$ years of age, are prone to failure of conservative treatment and, therefore, primary surgical intervention must be discussed in these cases.

- Currently, immobilization in abduction/external rotation seems to be the most effective approach, although further research is required.

- Short immobilization for 3 weeks should be followed by a guided rehabilitation protocol.

- Shoulder range of motion and strength should be symmetrical when compared to the uninjured side prior to return to play.

\section{Corresponding address}

Prof. Dr. Benedikt Schliemann

Department of Trauma, Hand and

Reconstructive Surgery, University Hospital

Münster, Albert-Schweitzer-Campus 1, building W1

48149 Münster, Germany

Benedikt.schliemann@ukmuenster.de

\section{Compliance with ethical guidelines}

Conflict of interest. B. Schliemann, M. Minkus, D. Seybold and M. Scheibel declare that they have no competing interests.

For this article no studies with human participants or animals were performed by any of the authors. All studies performed were in accordance with the ethical standards indicated in each case.

Open Access. This article is licensed under a Creative Commons Attribution 4.0 International License, which permits use, sharing, adaptation, distribution and reproduction in any medium or format, as long as you give appropriate credit to the original author(s) and the source, provide a link to the Creative Commons licence, and indicate if changes were made. The images or other third party material in this article are included in the article's Creative Commons licence, unless indicated otherwise in a credit line to the material. If material is not included in the article's Creative Commons licence and your intended use is not permitted by statutory regulation or exceeds the permitted use, you will need to obtain permission directly from the copyright holder. To view a copy of this licence, visit http://creativecommons.org/licenses/by/4.0/.

\section{References}

1. Rowe CR (1963) Anterior dislocations of the shoulder: prognosis and treatment. Surg Clin North Am 43:1609-1614

2. Hovelius $L$ (1999) The natural history of primary anterior dislocation of the shoulder in the young. JOrthopSci 4(4):307-317

3. Hovelius Let al (1996) Primary anterior dislocation of the shoulder in young patients. A tenyear prospective study. J Bone Joint Surg Am 78(11):1677-1684 
4. Hovelius L et al (2008) Nonoperative treatment of primary anterior shoulder dislocation in patients forty years of age and younger. a prospective twenty-five-year follow-up. J Bone Joint Surg Am 90(5):945-952

5. Finestone A et al (2009) Bracing in external rotation for traumatic anterior dislocation of the shoulder. JBone Joint Surg Br 91(7):918-921

6. Liavaag $S$ et al (2011) Immobilization in external rotation after primary shoulder dislocation did not reduce the risk of recurrence: a randomized controlled trial. J Bone Joint Surg Am 93(10):897-904

7. Whelan DB et al (2016) Immobilization in external rotation versus internal rotation after primary anterior shoulder dislocation: a meta-analysis of randomized controlled trials. Am J Sports Med 44(2):521-532

8. Hurley ET et al (2020) Arthroscopic Bankart repair versus conservative management for firsttime traumatic anterior shoulder instability: a systematic review and meta-analysis. Arthroscopy 36(9):2526-2532

9. Hasebroock AW et al (2019) Management of primary anterior shoulder dislocations: a narrative review. Sports Med Open 5(1):31

10. Kavaja $L$ et al (2018) Treatment after traumatic shoulder dislocation: a systematic review with a network meta-analysis. Br J Sports Med 52(23):1498-1506

11. Braun C, McRobert CJ (2019) Conservative management following closed reduction of traumatic anterior dislocation of the shoulder. Cochrane Database Syst Rev 5:CD4962

12. Gutkowska O, Martynkiewicz J, Gosk J (2017) Position of immobilization after first-time traumatic anterior glenohumeral dislocation: a literature review. Med Sci Monit 23:3437-3445

13. Paterson WH et al (2010) Position and duration of immobilization after primary anterior shoulder dislocation: a systematic review and metaanalysis of the literature. J Bone Joint Surg Am 92(18):2924-2933

14. Scheibel $M$ et al (2009) How long should acute anterior dislocations of the shoulder be immobilized in external rotation? Am J Sports Med 37(7):1309-1316

15. Minkus M et al (2018) Initial management of traumatic ventral shoulder dislocation. Unfallchirurg 121(2):100-107

16. Kralinger FS et al (2002) Predicting recurrence after primary anterior shoulder dislocation. Am J Sports Med 30(1):116-120

17. Itoi $E$ et al (2007) Immobilization in externa rotation after shoulder dislocation reduces the risk of recurrence. A randomized controlled trial. J Bone Joint Surg Am 89(10):2124-2131

18. Konigshausen $M$ et al (2014) Evaluation of immobilization in external rotation after primary traumatic anterior shoulder dislocation: 5-year results. Musculoskelet Surg 98(2):143-151

19. Murray JC et al (2020) Immobilization in external rotation after primary shoulder dislocation reduces the risk of recurrence in young patients. A randomized controlled trial. Orthop Traumatol Surg Res 106(2):217-222

20. Seybold D et al (2006) Immobilization in external rotation after primary shoulder dislocation. Chirurg 77(9):821-826

21. Taskoparan H et al (2010) Immobilization of the shoulder in external rotation for prevention of recurrence in acute anterior dislocation. Acta Orthop Traumatol Turc 44(4):278-284
22. Sullivan LG et al (2007) An evaluation of shoulder external rotation braces. Arthroscopy 23(2):129-134

23. Seybold D et al (2009) Which labral lesion can be best reduced with external rotation of the shoulder after a first-time traumatic anterior shoulder dislocation? Arch Orthop Trauma Surg 129(3):299-304

24. Miller BS et al (2004) Should acute anterior dislocations of the shoulder be immobilized in external rotation? A cadaveric study. J Shoulder Elbow Surg 13(6):589-592

25. Hart WJ, Kelly CP (2005) Arthroscopic observation of capsulolabral reduction after shoulder dislocation. JShoulder Elbow Surg 14(2):134-137

26. Itoi $E$ et al (2015) Arm abduction provides a better reduction of the Bankart lesion during immobilization in external rotation after an initial shoulder dislocation. Am J Sports Med 43(7):1731-1736

27. Heidari K et al (2014) Immobilization in external rotation combined with abduction reduces the risk of recurrence after primary anterior shoulder dislocation. JShoulderElbow Surg 23(6):759-766

28. Hatta T et al (2017) Comfort and acceptability of various immobilization positions using a shoulde external rotation and abduction brace. J Orthop Sci 22(2):285-288

29. Longo UG et al (2014) Management of primary acute anterior shoulder dislocation: systematic review and quantitative synthesis of the literature. Arthroscopy 30(4):506-522

30. Shinagawa Ketal (2020) Immobilization in external rotation reduces the risk of recurrence after primary anterior shoulder dislocation: a meta-analysis. Orthop J Sports Med 8(6):2325967120925694

31. Edouard P et al (2011) Rotator cuff strength in recurrent anterior shoulder instability. JBone Joint Surg Am 93(8):759-765

32. Lu Y et al (2020) Return to play and performance after shoulder instability in national basketball association athletes. J Shoulder Elbow Surg 29(1):50-57

33. Okoroha KR et al (2018) Return to play after shoulder instability in national football league athletes. J Shoulder Elbow Surg 27(1):17-22

34. Simonet WT, Cofield RH (1984) Prognosis in anterior shoulder dislocation. Am J Sports Med 12(1):19-24 